\title{
Description of the third instar larva and pupa of Macraspis morio Burmeister, 1844 (Coleoptera: Scarabaeidae: Rutelinae) from Southern Brazil
}

\author{
Bruno Piotrovski Begha, ${ }^{1,2}$ \& Mateus Henrique Santos ${ }^{1,3}$ \\ 1 Universidade Estadual de Ponta Grossa (UEPG), Departamento de Biologia Estrutural, Molecular e Genética (DEBIOGEN), \\ Programa de Pós-Graduação em Biologia Evolutiva (PPGBIOEVOL). Ponta Grossa, PR, Brasil. \\ 2 ORCID: http://orcid.org/0000-0001-8880-8247. E-mail: bpbegha@gmail.com \\ 3 ORCID: http://orcid.org/0000-0003-3063-1455. E-mail: marangonsantos@gmail.com
}

\begin{abstract}
The third instar larva and pupa of Macraspis morio Burmeister, 1844 (Rutelinae: Rutelini: Anticheirina), collected in Paraná, Brazil, is described and illustrations and comments are given. The larva differs from other Macraspis larvae by the head with 6 posterofrontal setae and mandibles with a blunt second left incisor tooth. The pupa is similar to that of M. festiva Burmeister, 1844.
\end{abstract}

Key-Words. Immature; Chaetotaxy; Neotropical; Taxonomy; White grub.

\section{INTRODUCTION}

The neotropical genus Macraspis MacLeay, 1819 (Rutelinae, Rutelini, Anticheirina), includes 66 described species (Roskov et al., 2019; Medeiros et al., 2019), distributed from Mexico to Argentina, of which 27 species are currently known in Brazil (Grossi \& Vaz-de-Mello, 2019).

Third-instar larva of Macraspis species is diagnosed by left mandible with incisor bearing three teeth, antennomere IV with four or more dorsal sensorial spots, and metapretarsus reduced and weakly sclerotized relative to propretarsus and mesopretarsus (Jameson \& Morón, 2001). The pupa is very simililar to those of other Rutelinae: adecticous, exarate, with reddish-brown body and well-developed meso-metaventrite process (Costa et al., 1988). Immature stages of Macraspis as well as other Rutelinae are usually found in rotten, humid wood or soil, feeding on decaying plant matter (Morón \& Paucar-Cabrera, 2003; Marshall, 2018).

Macraspis immatures are scarcely known. Until now, within the catalogued species only eight of them have their larva and pupa described (Medeiros et al., 2019; Albertoni et al., 2014). The objective of the present paper is to describe the immature stages of Macraspis morio Burmeister, 1844. We present illustrations and propose an update to the identification key of Medeiros et al. (2019) to include the larva of M. morio.
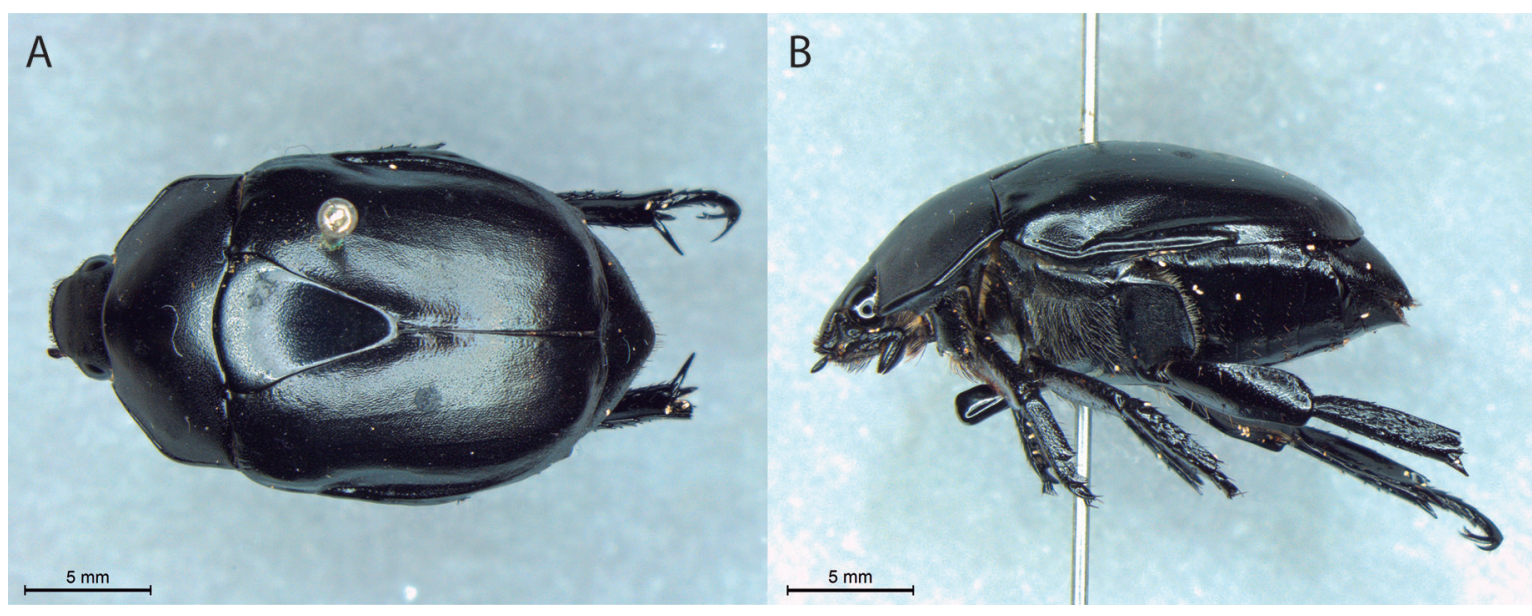

Figure 1. Macraspis morio Burmeister, 1844; habitus of reared female adult. (A) dorsal view; (B) lateral view, left.

Pap. Avulsos Zool., 2020; v.60: e20206034 http://doi.org/10.11606/1807-0205/2020.60.34

http://www.revistas.usp.br/paz

http://www.scielo.br/paz

Edited by: Simone Policena Rosa

Received: 28/01/2020

Accepted: $18 / 05 / 2020$

Published: $16 / 07 / 2020$
ISSN On-Line: 1807-0205

ISSN Printed: 0031-1049

ISNI: 0000-0004-0384-1825 


\section{MATERIAL AND METHODS}

The larvae were collected at the municipali-

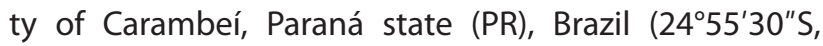
$50^{\circ} 04^{\prime} 51^{\prime \prime} \mathrm{W}$ ), inside rotten wood. A reared adult (Fig. 1) was sent to the Museu de Zoologia de São Paulo (MZSP) and was identified by Carlos Campaner. The larva was killed in hot water and preserved in alcohol $70 \%$. The adult was killed by being put in a freezer and later pinned. The specimens are housed in the Laboratório de Genética e Evolução of the Universidade Estadual de Ponta Grossa.

Photographs were taken with a Leica MC170 HD camera attached to a Leica M205 C stereomicroscope and processed using the Leica Application Suite (LAS) software 4.8.0. The photographs were edited using the software Adobe Photoshop. Illustrations were made using the software Adobe Illustrator based on the photographs.

The terminology used follows Böving (1936) and is in accordance with Carvalho et al. (2019) and Medeiros et al. (2019).

\section{RESULTS AND DISCUSSION}

\section{Macraspis morio Burmeister, 1844 Description of third larval instar}

(Figs. 2-7)

Body length: $10 \mathrm{~cm}$, width: $4.5 \mathrm{~cm}$; with yellowish white color, covered with brownish setae (Fig. 2A). Cranium
(Fig. 3) with vertex reddish-brown or light yellowish-brown; frons, clypeus, and labrum reddish-brown; mandibles dark reddish-brown. Surface of vertex nearly smooth, posterior area of frons sparsely punctate, anterior area of frons densely punctate. Stemmata (STM) present. Epicranial suture present. Each side of head with 4 dorsoepicranial setae (DES), 3 posteroepicranial setae (PES); 5-8 externoepicranial setae (EES), 2-3 anteroepicranial setae (AES), 6 posterofrontal setae (PFS), 1 externofrontal seta (EFS), 1 long anterofrontal angle seta (AAS); and 3-4 anterofrontal setae. Clypeus subtrapezoidal, each side with 2 externoclypeal setae (ECS), anteroclypeal setae absent. Antenna (Fig. 3) with four antennomeres, as long as mandibles. Antennomeres II and III subequal in length, IV shorter than III and with 7 dorsal sensorial spots (SPT) and 4-5 ventral sensorial spots. Epipharynx (Fig. 4A) with haptomerum moderately raised and with 23-26 spine-like setae, heli absent, epizygum indistinct. Acroparia with 9-11 stout setae. Left acanthoparia with 4 stout setae and right acanthoparia with 3 stout setae. Plegmata absent. Gymnoparia wide. Both sides of the chaetoparia with 15-17 inner stout setae and 13-15 outer thinner, smaller setae. Dexiotorma elongate. Laeotorma elongate and with pternotorma wide and rounded. Haptolachus with slightly sclerotized sensorial cone, sclerotized plate indistinct. Edges of the epipharynx well-sclerotized, with a darker brownish color. Labrum (Fig. 4B) subtrapezoid; with 4 preapical tubercles; each side with 8-11 anterolabral bristle-like setae (ALS); 3 laterolabral setae (LLS); 1 mediolabral
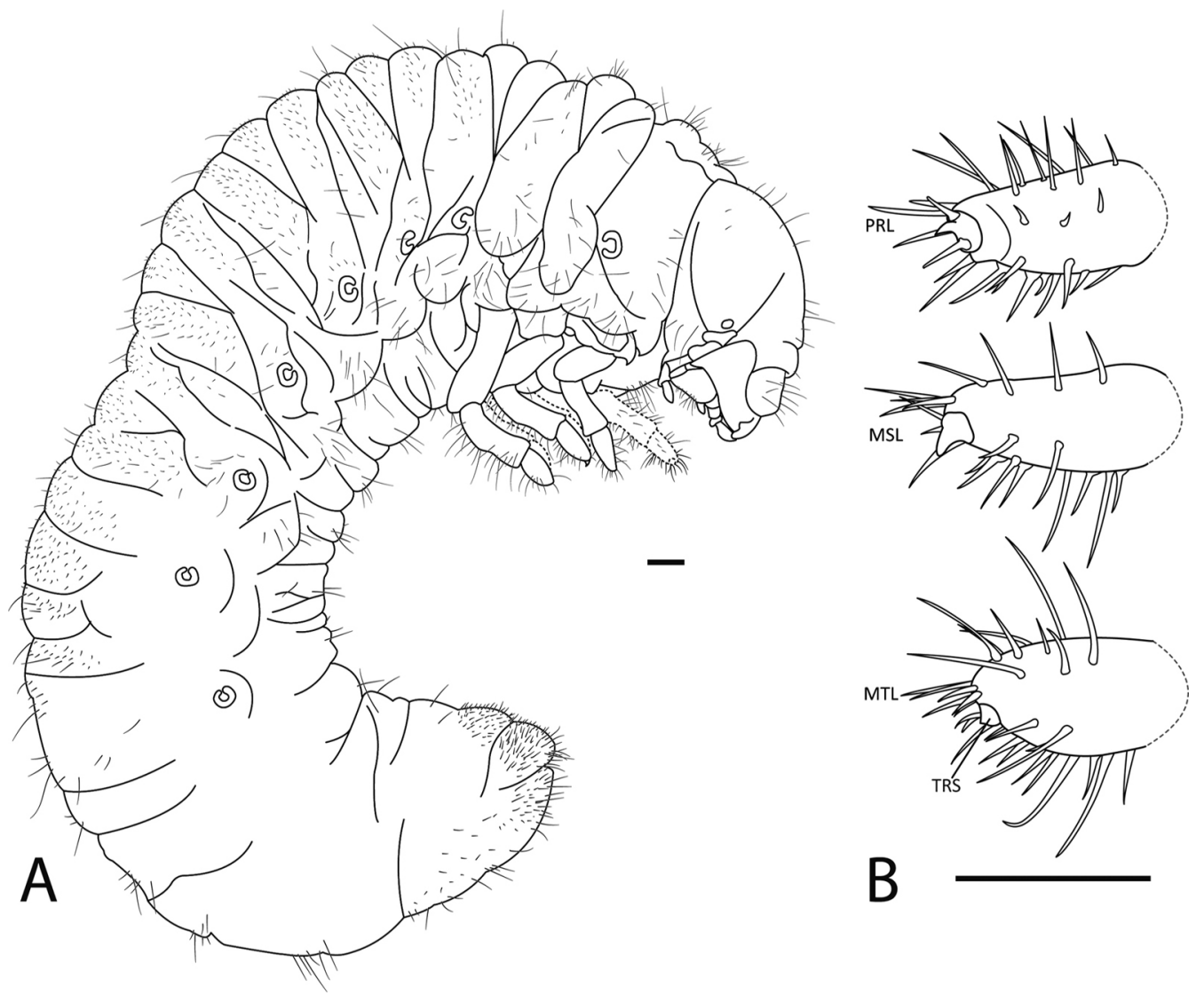

Figure 2. Macraspis morio Burmeister, 1844; third instar larva. (A) Lateral view; (B) right legs; inner view. PRL = protibiotarsus; MSL = mesotibiotarsus; $M T L=$ metatibiotarsus; $T R S=$ pretarsus. Scale $=1 \mathrm{~mm}$. 
seta on each side (MLS); and 5 posterolabral setae (PLS).

Left mandible (Figs. 5A, D) with incisor bearing 3 teeth (S1-S3), the second teeth with a blunt apex, not as sharp as the other incisors, apex blunt. Stridulatory area elongated and bearing 51 fine striae (STA). Molar (MLR) with
3 lobes (dorsal view). Calx (CLX) prominent, rectangular. Acia absent. Brustia (BTA) with 9-11 setae. Outer margin with 7 setae. Right mandible (Figs. 5B, C): incisor with 2 teeth (S1-S2). Stridulatory area with a slim-oval shape and bearing 44 fine striae, one ventral seta comb (VST).

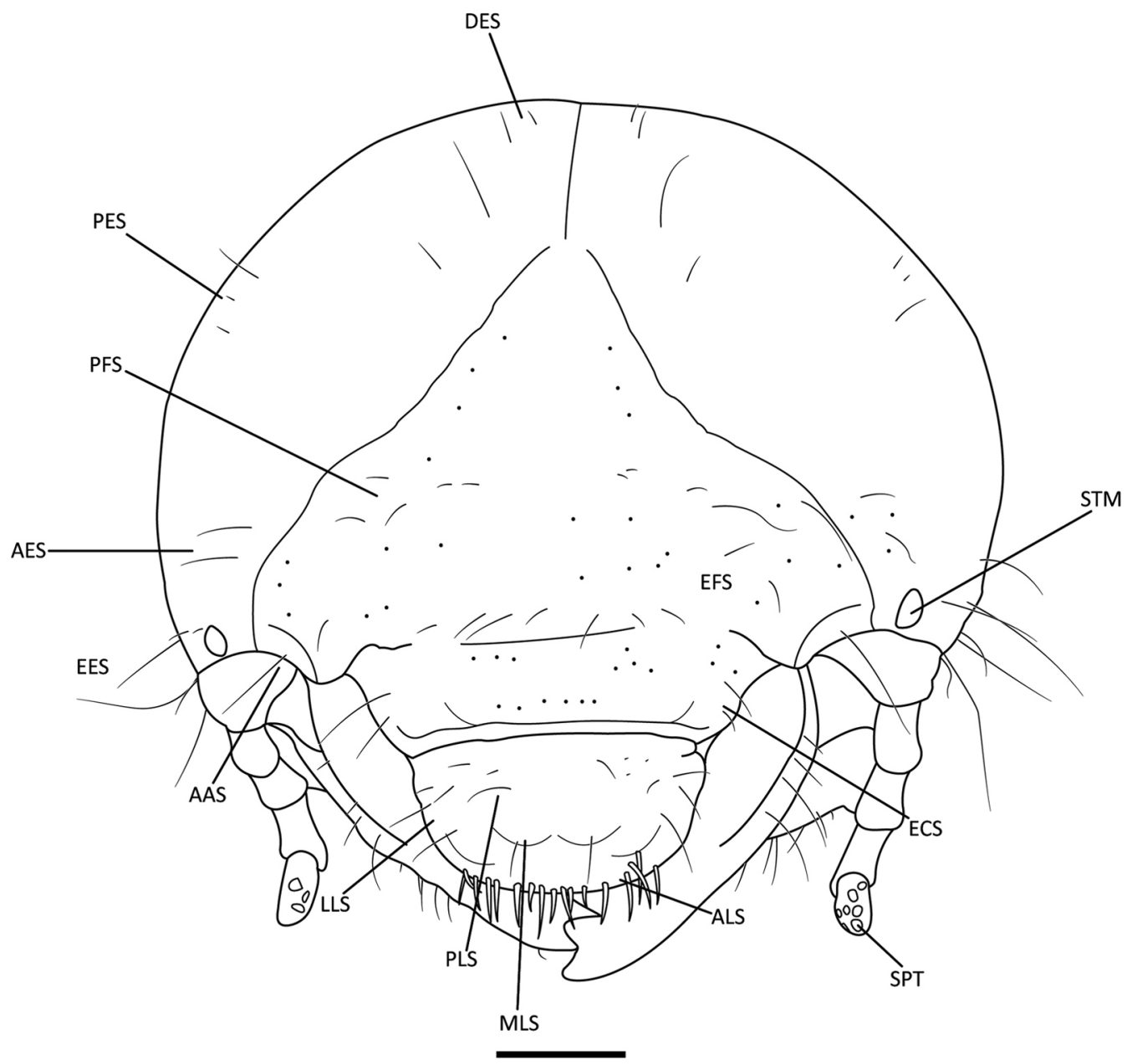

Figure 3. Macraspis morio Burmeister, 1844; third-instar larva, head, frontal view. $A A S=$ anterofrontal angle setae; $A E S=$ anteroepicranial setae; $A L S=$ anterolabral setae; $D E S=$ dorsoepicranial setae; $E C S=$ externoclypeal setae; $E E S=$ externoepicranial setae; $E F S=$ externofronal setae; $L L S=$ laterolabral setae; $M L S=$ mediolabral setae; $P E S=$ posteroepicranial setae; $P F S=$ posterofrontal setae; $P L S=$ posterolabral setae; $S P T=$ dorsal sensorial spots; $S T M=$ stemma. $S c a l e=1 \mathrm{~mm}$.

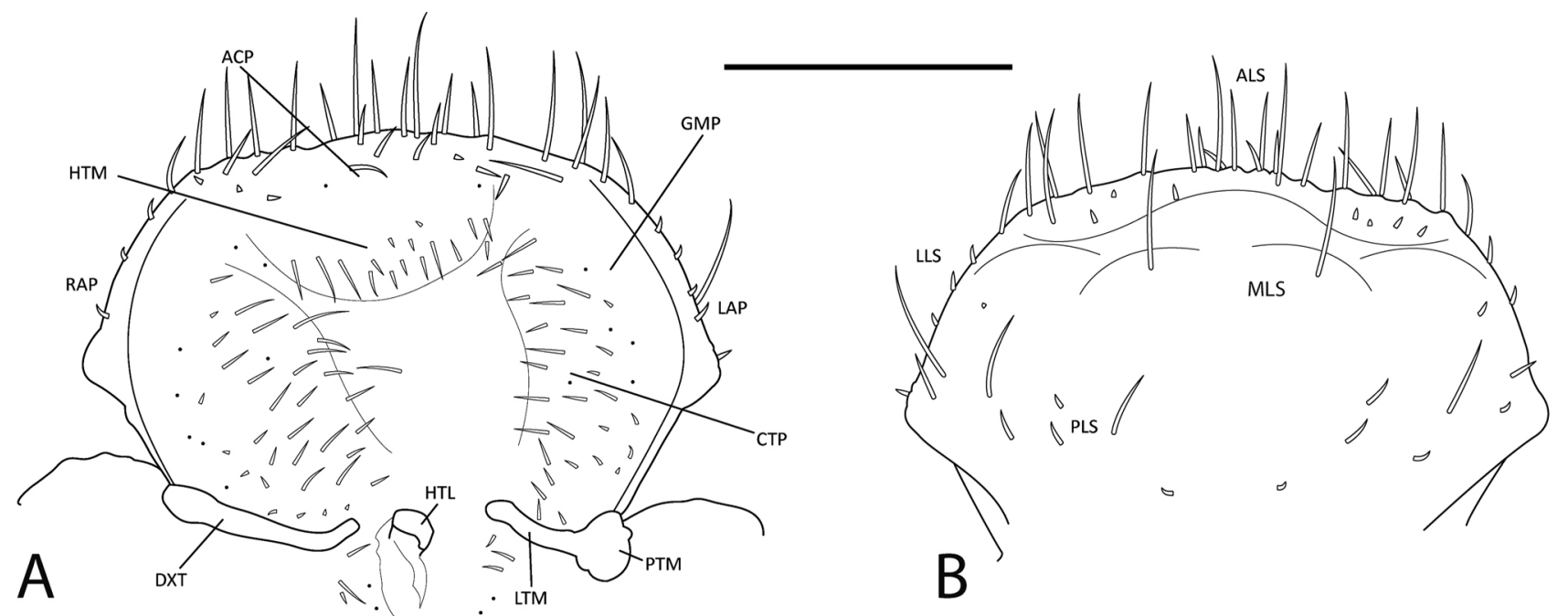

Figure 4. Macraspis morio Burmeister, 1844; third instar larva. (A) labrum, dorsal view; (B) epipharynx, ventral view. $A C P=$ acroparia; $A L S=$ anterolabral setae; $C T P=$ chaetoparia; $D X T=$ dexiotorma; $G M P=$ gymnoparia; $H T L=$ haptolachus; $H T M=$ haptomerum; $L A P=$ left acanthoparia; $L L S=$ laterolabral setae; $L T M=$ laeotorma; $M L S=$ mediolabral seta; $P L S=$ posterolabral setae; $P T M=$ pterotorma; $R A P=$ right acanthoparia. $S$ cale $=1 \mathrm{~mm}$. 


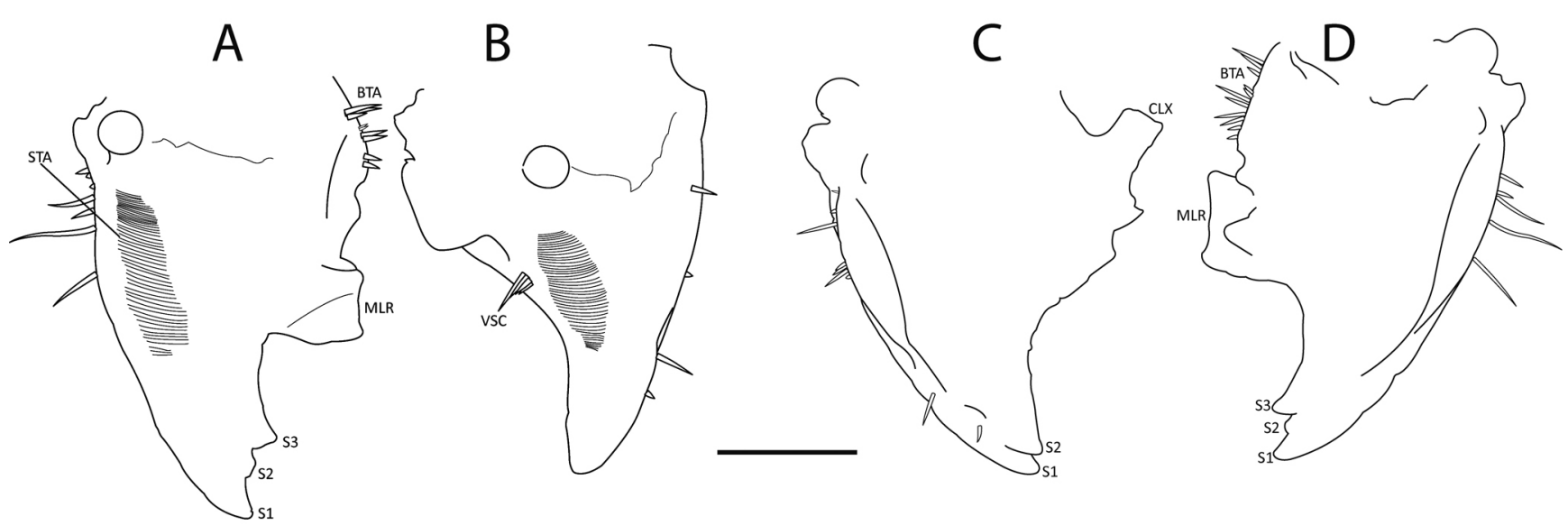

Figure 5. Macraspis morio Burmeister, 1844; third instar larva. (A) left mandible, ventral view; (B) right mandible, ventral view; (C) right mandible, dorsal view; (D) left mandible, dorsal view. $B T A=$ brustia; $C L X=$ calx; $M L R=$ molar lobe; $S 1-S 3=$ incisor teeth; $S T A=$ stridulatory area; $V S C=$ ventral setal comb. $S c a l e=1 \mathrm{~mm}$.

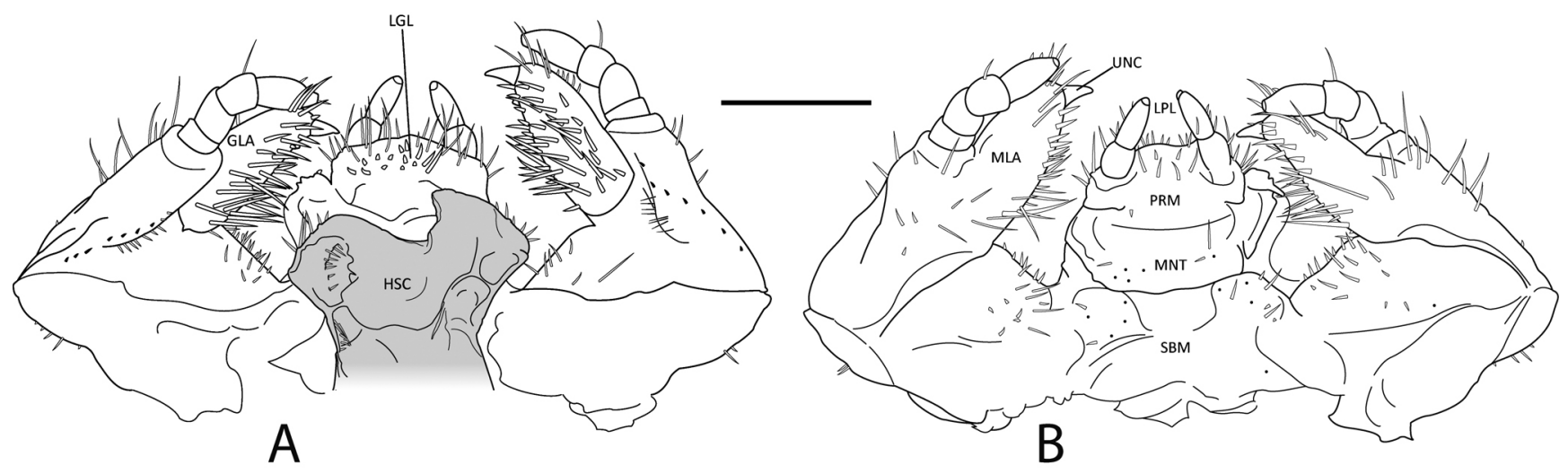

Figure 6. Macraspis morio Burmeister, 1844; third instar larva, maxilla and labium. (A) dorsal view; (B) ventral view. GLA = galea; HSC = hypopharyngeal sclerome; $L G L=$ ligula; $L P L=$ labial palpi; $M L A=$ mala; $M N T=$ mentum; $P R M=$ prementum; $S B M=$ submentum; $U N C=$ uncus. $S c a l e=1 \mathrm{~mm}$.

Brustia with 8-11 setae (BTA). Outer margin with 7 setae. Maxilla (Fig. 6) with galea and lacinia fused (forming the mala) (MLA). Galea (GLA) with a row of 7 stout setae in an inner row, apex with 1 large uncus (UNC) (Fig. 6A); lacinia with 1 small and blunt uncus; stipe with stridulatory area bearing 7 acute teeth. Maxillary palpus with 4 segments. Labium (Fig. 6) with prementum (PRM) with 6 medium setae between palps ( $L P L)$; mentum (MNT) with 2 setae on each side; submentum (SBM) with 6 setae on each side. Palps with 2 palpomeres. Hypopharynx (Fig. 6A) with hypopharyngeal sclerome (HSC) strongly asymmetrical, right side with raised tooth-like process. Right lateral lobe with 6 thin setae; left lateral lobe with about 15 mixed long and short setae. Ligula (LGL) with 22-25 long setae and 15-17 inner spine-like setae. Legs (Fig. 2B): metathoracic legs (MTL) larger than prothoracic (PRL) and mesothoracic legs (MSL). Pro- and mesopretarsus (TRS) slightly asymmetrical, short, and with 2 setae; metapretarsus reduced and with 2 setae. Thorax (Fig. 2A) with dorsal area sparsely setose. Spiracle in the mesothorax with a reniform, in "reversed-C" shape respiratory plate. Subequal in size to the VIII abdominal spiracle. Abdomen (Fig. 2A) with 8 spiracles along the lateral of the abdomen, with reniform respiratory plates, similar to each other. I-VI abdominal spiracles subequal in size,

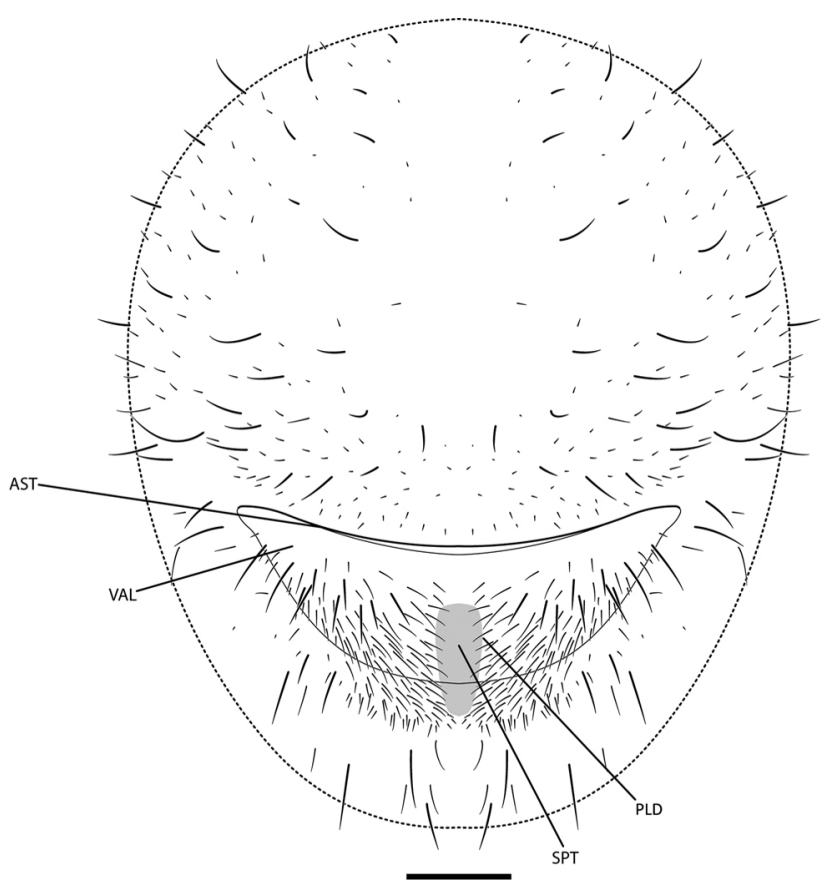

Figure 7. Macraspis morio Burmeister, 1844; third instar larva. Raster, rear view. $A S T=$ anal slit; $P L D=$ palidia; $V A L=$ ventral anal lobe; $S P T=$ septula (in grey); Scale $=1 \mathrm{~mm}$. 
VII-VIII slightly larger. Raster (Fig. 7) with each palidia (PLD) bearing 15-19 setae; septula (SPT) well defined with irregular margins. Palidia and septula are placed mainly on the ventral anal lobe (VAL), with a short part on the venter of last abdominal segment. Anal slit (AST) curved. Each side of tegillar area with more than 90 spine-like setae, with 30 preseptular setae.

Remarks: when compared to other species of the genus, the larva of M. morio can be distinguished by the following combination of characters: 6 posterofrontal setae, second incisor of the left mandible with a blunt apex, maxilla with 7 stridulatory teeth.

\section{Updated identification key for third instar larvae of Macraspis species (after Medeiros et al., 2019)}

1. Labrum without preapical tubercles, septula and palidia present at midline of ventral anal lobe..

- Labrum with preapical tubercles, septula and palidia present at most in anterior third of anal ventral lobe.

2. Each side of frons with 1 posterofrontal seta and 1 externofrontal seta; antennomere IV with 7 dorsal sensorial spots; labrum irregularly convex, without keel; maxilla with 6 stridulatory acute teeth ........... ...Macraspis pseudochrysis Landin, 1956
- Each side of frons with 2 posterofrontal setae and without externofrontal setae; antennomere IV with 5 dorsal sensorial spots; labrum convex and with weak preapical transverse keel; maxilla with 8 stridulatory acute teeth... Macraspis festiva Burmeister, 1844

3. Each side of epicranium with 3 dorsoepicranial setae; labrum with 2 preapical tubercles

- Each side of epicranium with 4-5 dorsoepicranial setae; labrum with 4 preapical tubercles

4. Cranium yellowish red; antennomere IV with 5 dorsal sensorial spots; each side of labrum with 2-4 posterolabral setae; haptomerum with 19-20 spine-like setae; each palidium with 20-23 pali

...Macraspis rufonitida Burmeister, 1844

- Cranium reddish brown; antennomere IV with 4 dorsal sensorial spots; each side of labrum with 10-14 posterolabral setae; haptomerum with 30-34 spine-like setae; each palidium with 11-18 pali.

Macraspis chrysis (Linnaeus, 1764)

5. Each side of frons with more than 1 posterofrontal seta; labrum with 4 posterolabral setae; maxilla with 7-9 acute stridulatory teeth .......6 6

- Each side of frons with 1 posterofrontal seta; labrum with 6-12 posterolabral setae; maxilla with 5-6 acute stridulatory teeth ....... 8

6. Each side with 6 posterofrontal setae.

...Macraspis morio (Burmeister, 1844)

- Each side with 2-3 posterofrontal setae

7. Each side of epicranium with 5 dorsoepicranial setae; antennomere IV with 4 dorsal sensorial spots; each palidium with 20-24 pali Macraspis cribrata Waterhouse, 1881
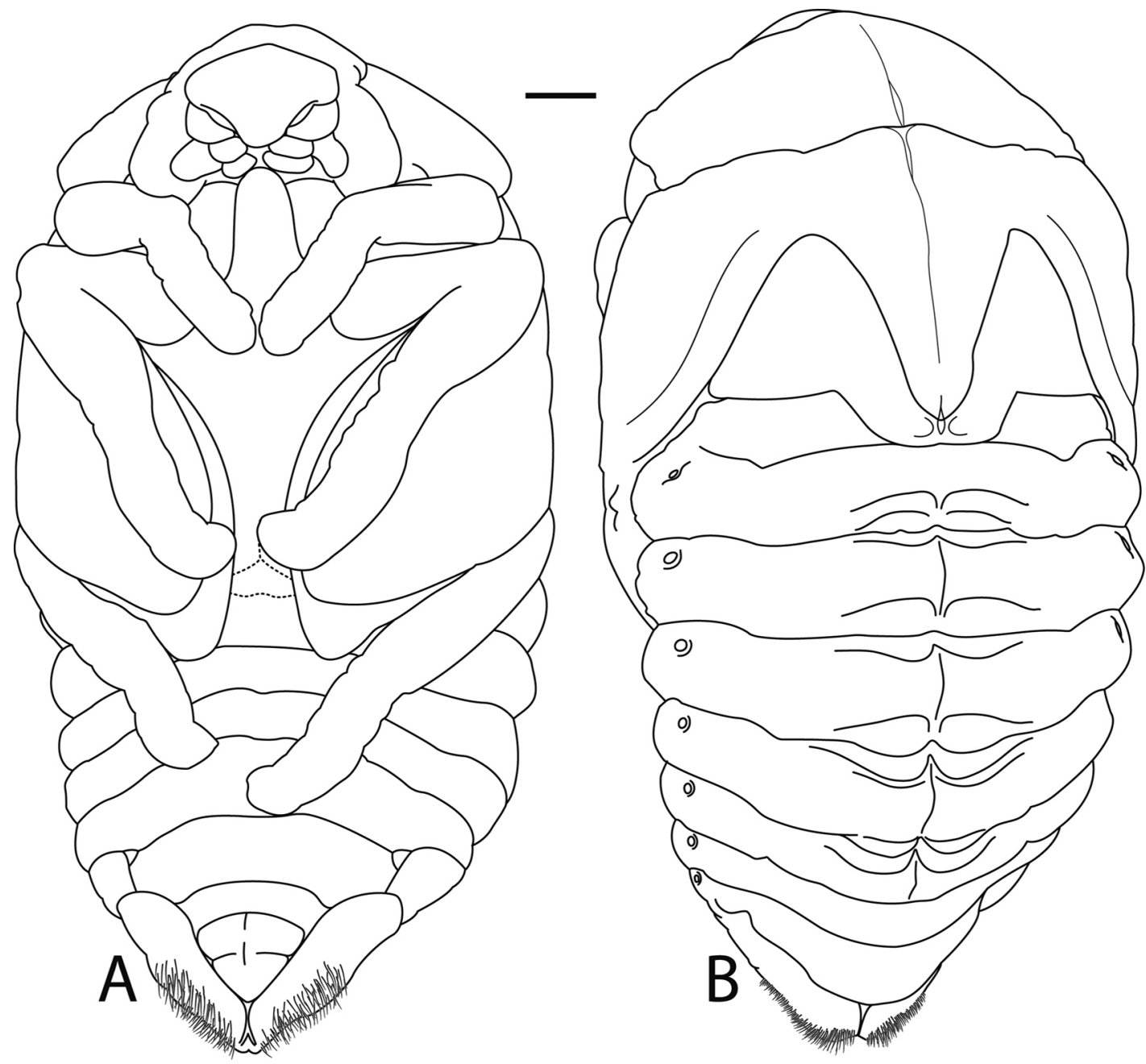

Figure 8. Macraspis morio Burmeister, 1844; female pupa; (A) dorsal view; (B) ventral view. Scale $=1 \mathrm{~mm}$. 
- Each side of epicranium with 4 dorsoepicranial setae; antennomere IV with 5-6 dorsal sensorial spots; each palidium with 26-30 pali........ Macraspis cincta (Drury, 1782)

8. Each side of clypeus with 1 anteroclypeal seta and 4-5 short externoclypeal setae, antennomere IV with 6 dorsal sensorial spots and 5 ventral sensorial spots... Macraspis aterrima Waterhouse, 1881

- Each side of clypeus with 2 anteroclypeal setae and 2 long externoclypeal setae, antennomere IV with 8 dorsal sensorial spots and 8 ventral sensorial spots ..........Macraspis clavata (0livier, 1789)

\section{Description of female pupa} (Fig. 8)

Body lenght: $13 \mathrm{~cm}$; width: $7.1 \mathrm{~cm}$; shape oval, reddish-brown. Body surface glabrous, except at apex of the abdomen, that is covered by many small hairs. Meso- and metaventrite with an anterior keel-like projection.

Head ventrally directed, slightly visible from above; clypeus inflated, triangular; clypeofrontal suture sinuate; labrum, mandibles, maxillae, and palpi discernible, tubercle-like, antennal thecae rounded. Thorax with pronotum convex, margins curved. Posterior margin of mesonotum posteriorly expanded, the medial portion almost reaching the posterior margin of metanotum. Posterior margin of metanotum expanded medially, posterior projection covering the middle of the first abdominal tergite. Elytral and hind wing thecae curved ventrally around the body; elytral thecae extending to second abdominal segment; hind wing thecae extending to third abdominal segment, covering the metafemur in ventral view; legs with tarsomeres distinct. Abdomen with tergites II-VI with 4 pairs of gin traps between II-III, III-IV, IV-V, and V-VI; tergite IX with posterior area bearing dense, minute, reddish-brown setae. Spiracles of abdominal segment I hidden under posterior border of the hind wing thecae; spiracles II-IV visible, larger and darker, apparently functional with peritreme, spiracles V-VII closed and without peritreme. Urogomphi absent, tergite IX lateroventrally folded; fold posterior area rounded.

Remarks: when compared to pupae of other Rutelini, Macraspis can be identified by the long thoracic ventrite process that is extended between anterior legs, whilst other species, alike Chlorota and Lagochile, have the thoracic ventrite not prominent between anterior legs (Costa et al., 1988; Albertoni et al., 2014). When compared to other members of its genus, $M$. morio is very similar to $M$. festiva, with the fold in the abdominal tergite IX reddish brown with short setae and a frontoclypeal suture somewhat straight and medially indistinct (Bento et al., 2018).

\section{ACKNOWLEDGMENTS}

We thank the reviewers for their valuable comments and suggestions, Carlos Campaner (MZSP) for identifying the adult, Edna Maria Amaral (UEPG) for collecting and rearing the larvae; CAPES (Coordenação de Aperfeiçoamento de Pessoal de Nível Superior) for providing the financial support; UEPG (Universidade Estadual de Ponta Grossa), LabGEv (Laboratório de Genética e Evolução) and PPG-BioEvol (Programa de Pós-Graduação em Biologia Evolutiva) for providing the infrastructure.

\section{REFERENCES}

Albertoni, F.F.; Fuhrmann, J. \& Ide, S. 2014. Lagochile emarginata (Gyllenhal): morphology of immature and imago, and biological records (Coleoptera, Scarabaeidae, Rutelinae). Revista Brasileira de Entomologia, 58: 32-46. DOI

Bento, M.; Fuhrmann, J. \& Bevilaqua, M.V.0. 2018. Description of the pupa of Cnemida retusa (Fabricius, 1801) (Melolonthidae: Rutelinae). Papéis Avulsos de Zoologia, 58(56): 1-6. D0I

Böving, A.G. 1936. Description of the larva of Plectris aliena Chapin and explanation of new terms applied to the epipharynx and raster. Proceedings of the Entomological Society of Washington, 38: 169-185.

Carvalho, T.G.; Duarte, P.R.M.; Fuhrmann, J. \& Grossi, P.C. 2019. Description of the last larval instar and pupa of Chlorota paulistana Ohaus, 1912 (Coleoptera: Melolonthidae: Rutelinae: Rutelini). Revista Brasileira de Entomologia, 63: 245-249. D0I

Costa, C.; Vanin, S.A. \& Casari-Chen, S.A. 1988. Larvas de Coleoptera do Brasil. São Paulo, Museu de Zoologia, Universidade de São Paulo. 447p.

Grossi, P.C. \& Vaz-de-Mello, F.Z. 2019. Melolonthidae in Catálogo Taxonômico da Fauna do Brasil. PNUD. Available at: http://fauna.jbri.gov.br/fauna/ faunadobrasil/127303. Access in: 12/08/2019.

Jameson, M.L. \& Morón, M.Á. 2001. Descriptions of the larvae of Chlorota cincticollis Blanchard and Chasmodia collaris (Blanchard) (Scarabaeidae: Rutelinae: Rutelini) with a key to the larvae of the American genera of Rutelini. The Coleopterists Bulletin, 55(3): 385-397. D0I

Marshall, S.A. 2018. Beetles: The natural history and diversity of Coleoptera. Richmond Hill, Firefly Books.

Medeiros, R.A.; Frazão, C.A.; Grossi, P.C. \& Fuhrmann, J. 2019. Description of the third instar of Macraspis clavata (Olivier, 1789) (Coleoptera: Scarabaeidae: Rutelinae). Zootaxa, 4638(3): 442-450.

Morón, M.A. \& Paucar-Cabrera, A. 2003. Larvae and pupae of species of the genus Macraspis (Coleoptera: Scarabaeidae: Rutelinae: Rutelini). The Canadian Entomologist, 135(4): 467-491.

Roskov, Y.; Ower, G.; Orrell, T.; Nicolson, D.; Bailly, N.; Kirk, P.M.; Bourgoin, T.; DeWalt, R.E.; Decock, W.; Nieukerken, E.; Zarucchi, J.; Penev L. (Eds.). 2019. Species 2000 \& ITIS Catalogue of Life, 2019 Annual Checklist. Available at: www.catalogueoflife.org/annual-checklist/2019. Access in: 23/01/2020. 